\title{
PERCEPTION OF RISK OF HIV/AIDS AND SEXUAL BEHAVIOUR IN KENYA
}

\author{
PRISCILLA A. AKWARA*, NYOVANI JANET MADISE $†$ AND \\ ANDREW HINDE $\dagger$ \\ * Macro International Inc., 11785 Beltsville Drive, Calverton MD 20705, USA and \\ $\dagger$ Department of Social Statistics, University of Southampton, Southampton SO17 1 BJ, \\ $U K$
}

\begin{abstract}
Summary. The association between perception of risk of HIV infection and sexual behaviour remains poorly understood, although perception of risk is considered to be the first stage towards behavioural change from risk-taking to safer behaviour. Using data from the 1998 Kenya Demographic and Health Survey, logistic regression models were fitted to examine the direction and the strength of the association between perceived risk of HIV/AIDS and risky sexual behaviour in the last 12 months before the survey. The findings indicate a strong positive association between perceived risk of HIV/AIDS and risky sexual behaviour for both women and men. Controlling for sociodemographic, sexual exposure and knowledge factors such as age, marital status, education, work status, residence, ethnicity, source of AIDS information, specific knowledge of AIDS, and condom use to avoid AIDS did not change the direction of the association, but altered its strength slightly. Young and unmarried women and men were more likely than older and married ones to report risky sexual behaviour. Ethnicity was significantly associated with risky sexual behaviour, suggesting a need to identify the contextual and social factors that influence behaviour among Kenyan people.
\end{abstract}

\section{Introduction}

Studies that have examined the association between the perception of risk and sexual behaviour remain inconclusive because of the difficulty of disentangling the complex relationship between the two variables (Cleland, 1995). The meaning and context of sexuality vary across populations and cultures, and this has been demonstrated to have a major impact on sexual behaviour. Bongaarts $(1995$, p. 9) states that 'sexual behaviour is probably responsible for much of the differences in heterosexual HIV/AIDS epidemics among countries, as well as for the equally large differences among regions and demographic groups within countries'. It has been suggested that 
in sub-Saharan Africa, sexual activity appears to be driven largely by sociocultural beliefs and practices (Caldwell, Orubuloye \& Caldwell, 1999; Cohen \& Trussell, 1996; Gage \& Njogu, 1994; Anarfi, 1993). Risk-taking sexual behaviour may be tolerated in some contexts while in others it may be strongly disapproved of and regarded as irresponsible or immoral. For example, multiple partnerships for men may be tolerated, while women's infidelity is highly penalized, meaning that aspects of sexual conduct are beyond womens' control (Caldwell et al., 1999; Fapohunda \& Rutenberg, 1999; Ingham \& van Zessen, 1997).

Risk-taking sexual behaviour in sub-Saharan Africa is associated with a number of factors, including gender inequalities that place women in subordinate positions, the belief that men have stronger sexual drives than women, and the notion that men cannot do without sex (Reid, 1999; Kenya et al., 1998; Cohen \& Trussell, 1996; Ocholla-Ayayo \& Schwarz, 1991). These beliefs act to exacerbate the spread of sexually transmitted diseases (STDs), including HIV/AIDS. The lack of power to negotiate safer sex among women may be the central obstacle to AIDS prevention in Africa. Sexual behaviour may not be under an individual's volition but may be dependent upon the social and cultural environment in which one lives. The ability of individuals to be aware of, to initiate, and to sustain safer sexual behaviours may largely depend upon societal sexual norms and practices, and not just self-perceived susceptibility to HIV infection.

Using the Kenya Demographic and Health Survey (KDHS) data of 1998, this paper examines the direction and strength of the association between the perception of the risk of HIV/AIDS and the sexual behaviour of men and women, net of sociodemographic and psychosocial knowledge factors. An examination of people's perceptions of HIV risk is important in understanding how people relate their sexual experiences to the risk of disease infection. Perceived risk of getting AIDS may have important implications for health if the perceptions are rational and lead to a willingness to avoid risky behaviour. In addition, an understanding of the association between perception of risk and sexual behaviour may facilitate the design of AIDS-preventive measures necessary to check the spread of the disease among different population subgroups.

\section{Background}

Kenya is one of the countries in sub-Saharan Africa most affected by the AIDS epidemic, despite high levels of awareness of the disease. Recent estimates of prevalence levels of HIV/AIDS in Kenya indicate that in 1990, about half a million people were living with HIV and by 2000, the number had increased to just over two million people (Government of Kenya/AIDS Control Unit et al., 2001). The percentage of adults aged 15 and above infected with HIV is estimated at $14 \%$ overall, $17 \%$ in urban areas and $12 \%$ in rural areas, though the rural-urban gap is narrowing (Government of Kenya/AIDS Control Unit et al., 2001).

Kenya is divided into eight regions, subdivided into over 75 districts, and HIV prevalence varies by region. Regions in Kenya are also ethnically oriented, with specific ethnic groups predominant in some areas. Consistently high HIV/AIDS prevalence rates from sentinel surveillance data have been noted in Nyanza, Nairobi 
and parts of Western and Rift Valley Provinces, where rates among pregnant women range from $16 \%$ to $30 \%$ (Government of Kenya/AIDS Control Unit et al., 2001). The rising prevalence rates may be attributed in part to the long latency period of the HIV virus in the human body so that those infected years ago are coming to light only now. In addition, differences in sociocultural beliefs and practices among communities and the level of people's integration through labour and rural-urban migration may be contributory factors to the recent sudden upsurge of prevalence rates in some previously low HIV/AIDS regions.

The age and sex distributions of AIDS cases in Kenya show that men and women are infected in equal proportions (National Council for Population and Development et al., 1999). This is expected as HIV is predominantly transmitted through heterosexual contact, accounting for at least $80 \%$ of adult HIV infections (UNAIDS, 2000a). About 75\% of the AIDS cases occur in the age group 20-45 years, peaking at ages 25-29 years for females and 30-34 years for males. Young women in the age groups 15-24 years are 2-3 times more likely to be infected than males in the same age group (Government of Kenya/AIDS Control Unit et al., 2001; Baltazar et al., 1999; Okeyo et al., 1998).

Since 1985 the Government of Kenya, with the support of the United Nations and other bilateral agencies, non-governmental organizations, community-based organizations and religious institutions, has made tremendous efforts towards addressing the AIDS problem. In 1987 the National AIDS Control Programme was established. At the time, AIDS was not seen as a serious problem and so the focus was on creating AIDS awareness, blood safety, clinical management of AIDS-related opportunistic infections, and capacity building for the management of AIDS control programmes at the national level. In 1992 it was apparent that HIV prevalence rates were steadily increasing, and to stem the accelerated spread of AIDS, STD control was seen as a priority since STDs facilitate the transmission of HIV (Wasserheit, 1992; Simonsen et al., 1990). This led to the integration of STD control into AIDS programmes, thus establishing the National AIDS and STD Control Programme in 1994 (Government of Kenya/AIDS Control Unit et al., 2001).

The AIDS policy prompted national debates and pronouncements about the causes and implications of the spread of AIDS in Kenya. This led to President Moi publicly declaring the disease a national disaster in November 1999. Following the president's public acknowledgement of the AIDS threat, and as recommended by the AIDS Policy of 1997, the National AIDS Control Council was established in 1999 to co-ordinate a multi-sectoral approach to AIDS prevention and mitigation.

Public AIDS awareness campaigns in Kenya emphasize change in sexual behaviour, including abstinence, condom use, monogamy and reduction of sexual partners. The assumption is that people will respond to risk in a way that reflects their HIV/AIDS awareness levels. This assumption relies heavily on the Health Belief Model (Becker, 1974). So far, some major achievements are evident from the various interventions undertaken in Kenya. Over $99 \%$ of both women and men are aware of AIDS and $96 \%$ know of its sexual transmission. According to the Kenya Demographic and Health Surveys of 1993 and 1998, the number of people with misconceptions about AIDS has decreased over the last few years. In 1998, only 8\% gave incorrect responses when asked about modes of HIV transmission, compared 
with $50 \%$ in 1993. Although ignorance is no longer an issue, it remains unclear how perception of risk influences people's sexual behaviour. Literature suggests that people seem to make judgements about risk based on a host of factors and not just on their knowledge of AIDS risk (Nzioka, 1996; 2001; Ingham \& van Zessen, 1997).

\section{Conceptual framework}

It is important to understand the context of risk perception in relation to sexual behaviour because it is the first stage towards behavioural change from risk-taking to safer sex. Although health behaviour models acknowledge the centrality of perceived risk in behavioural change (Becker \& Joseph, 1988; Becker, 1974), it is unclear how people's personal risk assessments relate to their sexual behaviour.

A review of quantitative and qualitative studies shows that individuals are more likely to underestimate than to overestimate their risk of HIV infection regardless of the nature of their sexual behaviour (Nzioka, 2001; Aggleton et al., 1994; Ingham \& van Zessen, 1997; Becker \& Joseph, 1988). People often rationalize risk-taking behaviour using a range of socially constructed criteria that could explain the apparent mismatch between objective risk and perceived risk (Abrams et al., 1990). Using in-depth interviews to examine lay perceptions of risk of HIV infection in one community in Kenya, Nzioka (1996, p. 576) found that people constructed risk in ways 'which were socially meaningful but which neither limit the spread of the virus nor offer security to the individual from the virus'. A qualitative study in Kenya found that although AIDS was perceived as a great threat in focus group discussions, individuals did not necessarily perceive themselves to be at risk (Idele, 2002).

Risky sexual behaviour can be viewed in the context of the number and types of partnerships, sexual acts, and orientation (Cohen \& Trussell, 1996; Dixon-Mueller, 1996). Other elements of risky sexual behaviour include early age at first sexual intercourse, multiple sexual partners, unprotected sexual intercourse with 'at risk' sexual partners, and untreated sexually transmitted diseases. The link between perception of risk and sexual behaviour can work both ways. Individuals may perceive their risk of getting AIDS to be high or low depending on their previous sexual behaviour or that of their partners. In this case, risky sexual behaviour is the influencing factor on perception of risk. In some cases, a person's perception of risk may be passive, and not necessarily based on his or her previous sexual behaviour. A high perception of risk might lead to a modification of sexual behaviour, for example refusal to have sexual intercourse with a partner.

The conceptual framework (Fig. 1) identifies two outcome variables: perception of risk of HIV infection and sexual behaviour. In this paper, the focus is on sexual behaviour as the dependent outcome, so perception of risk is treated as an explanatory variable although the association can operate in the other direction. Figure 1 shows the possible associations between a range of background factors at the national, community and individual levels, intermediate sociodemographic and psychosocial factors and the outcome factors.

Although they are not considered in this analysis, at the national level, political will and commitment to policies on HIV/AIDS prevention and reproductive health can influence individuals' access to information and to services such as voluntary 
Background

\begin{tabular}{l}
$\begin{array}{l}\text { National Level } \\
\text { Programmes and } \\
\text { policies on HIV/AIDS } \\
\text { Policies on education, } \\
\text { employment, gender, } \\
\text { economy. }\end{array}$ \\
\hline \multicolumn{1}{|c|}{} \\
\multicolumn{1}{|c|}{} \\
\hline
\end{tabular}

\begin{tabular}{|l|}
\hline Individual level \\
Age \\
Sex \\
Ethnicity \\
Religion \\
\hline
\end{tabular}

Intermediate

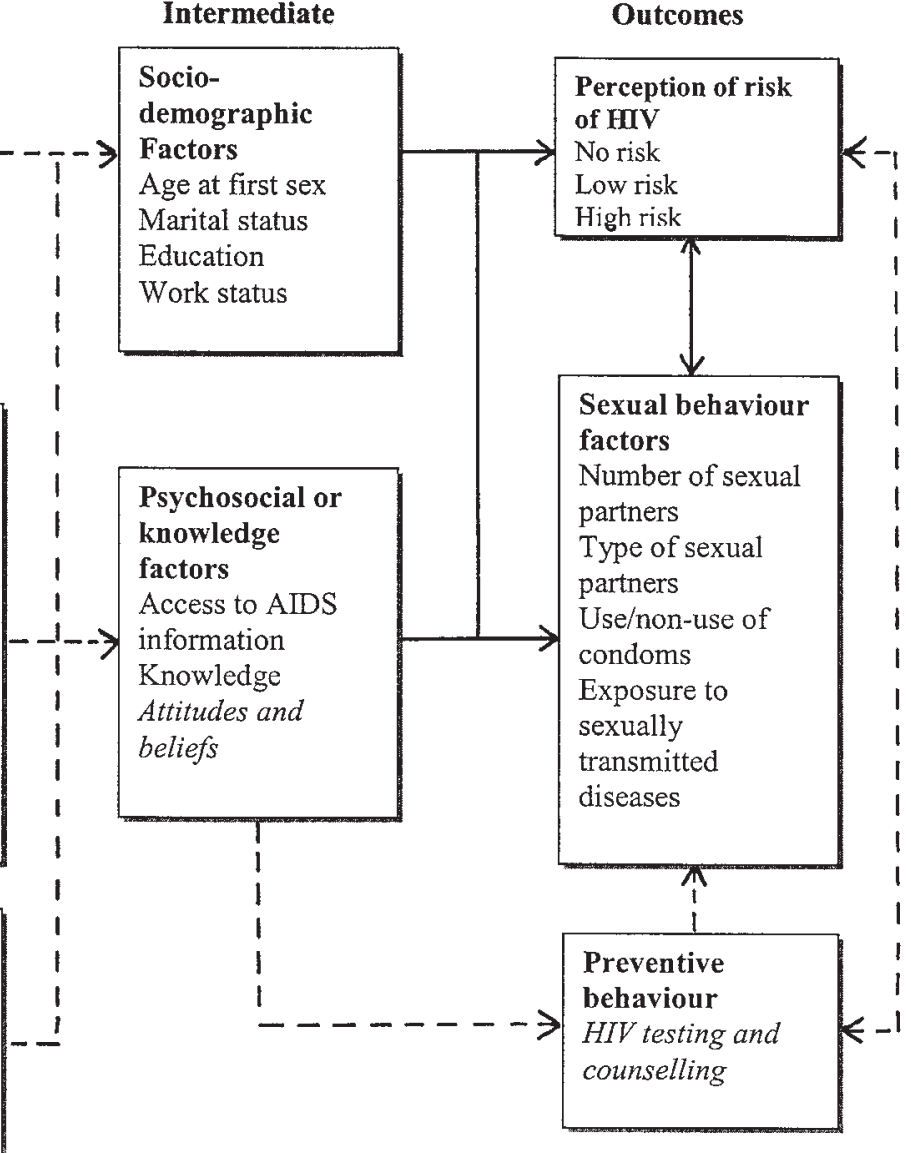

Fig. 1. A conceptual framework for the study of perception of risk of HIV infection and sexual behaviour in Kenya. The solid lines represent associations that are examined in this paper; the dotted lines represent possible associations, but those that are not tested in this paper. The variables in italics are not measured in this study.

counselling and testing or treatment of sexually transmitted diseases. These may in turn influence individuals' perception of HIV risk and sexual behaviour. The importance of political will and commitment is demonstrated by Uganda's success in controlling the spread of HIV (UNAIDS, 1998). Other national policies and programmes such as those on education, the economy, employment, marriage, divorce and gender may also influence individuals' sexual behaviour and the spread of HIV. Such policies can affect the availability of community-level health services, the distribution of economic resources, transportation, communication, urbanization, gender roles and the empowerment of women.

At a community level, ideologies of masculinity and femininity may help to shape an individual's identity and self-concept and may thus have a strong impact on his 
or her role in sexual decision-making (Gage, 1998). For instance, social norms may define 'a good woman' as one ignorant of sex or passive in sexual encounters, whereas a 'real man' may be defined as being sexually experienced, possibly with several partners. The socialization of young women to acquiesce to spouses in sexual encounters and to give priority to male pleasure and control in sexual partnerships can contribute significantly to women's inability to negotiate when, where and how sexual intercourse takes place (Family Health International, 1999). Region of residence, and whether a person lives in an urban or rural area, can determine the level of access to information and reproductive health services, which could influence sexual behaviour and perception of risk. Region of residence and rural or urban location are measured in this paper.

The conceptual framework includes some individual background factors, such as gender, current age, ethnicity and religion, that may influence sexual behaviour. Evidence from the literature suggests that women have fewer sexual partners than do men, and women with little control over the sexual activities of their partners are vulnerable to infection by these partners (Family Health International, 1999; Reid, 1999; Orubuloye et al., 1997; Caraël, 1995; Ingham \& Holmes, 1991). Women are 2-4 times more likely than men to become infected with STDs after intercourse with an infected partner due to physio-biological differences and their low socioeconomic position (UNAIDS, 2000a; Family Health International, 1999; Cohen \& Trussell, 1996; Mason, 1994).

The age of a person is another factor that may influence sexual behaviour and the level of perceived risk of HIV infection. Men and women in their teens are at increased risk of HIV infection because they often engage in unprotected sexual intercourse (Hulton et al., 2000). Sometimes there is pressure for girls to prove their fertility before marriage. Similarly, boys may face pressure to prove manhood by impregnating a girl, or by having many sexual partners (Meekers \& Calvès, 1997; Nzioka, 2001). Although the risk of HIV infection is high among young men and women, often they do not perceive their risk to be high (Prohaska et al., 1990; Cleland, 1995).

Ethnicity may influence sexual behaviour through cultural beliefs and practices. For example, the practice of levirate marriage, where a dead man's widow is remarried to one of his brothers, is still being practised in some areas of sub-Saharan Africa, despite the high prevalence of HIV (Ocholla-Ayayo, 1976, 1997; Standing \& Kisekka, 1989; Degrees du Lou, 1999). Among the Luo and Luhya of Western Kenya, widows sometimes have sexual intercourse with a male relative of the deceased as ritual 'cleansing' (Kenya et al., 1998; Ocholla-Ayayo \& Schwarz, 1991). Another risky sexual practice is that of 'wife-sharing', which has been reported among the Maasai of Kenya (Lesthaeghe, 1989). The pressure to conform to cultural beliefs and practices may override concerns about HIV infection.

Religion can influence sexual behaviour through intermediate factors such as the age at first sex, marital status, and access to information and services. It can also influence attitudes to HIV and perception of risk. Nzioka (1996), using in-depth interviews among people living with HIV/AIDS and opinion leaders, noted that religious people considered AIDS to be a disease that affected those who transgressed against God. Consequently, those who were religious perceived their risk of HIV 
infection to be low. Religion can also work to influence community practices and national policies. The Kenyan national AIDS programmes faced opposition from religious leaders at the onset, particularly on the issue of introducing sex education in schools and on condom use, which were thought to encourage promiscuity (Forsythe et al., 1996).

The conceptual framework assumes that the background factors operate through a range of intermediate factors to influence perception of risk and sexual behaviour. These intermediate factors may be sociodemographic (such as sexual initiation, marital status, the level of education and work status) or psychosocial (like access to information, knowledge, attitudes and beliefs). These two types of intermediate factors are described next.

Unless the first intercourse is also the start of a mutually monogamous relationship, early age at first sexual intercourse is associated with a long period of exposure to sexual activity, a higher propensity to accumulate sexual partners, and increased chances of contracting sexually transmitted diseases (Dixon-Muller \& Wasserheit, 1990; Konings et al., 1994)

Marital status influences perception of the risk of HIV infection and sexual behaviour. Whereas non-married women may have some ability to negotiate safer sex, married women face extra challenges because of the fear of being suspected of promiscuity by their spouses, which may lead to unwanted consequences such as separation or even divorce. Often, married women acquiesce in unsafe sexual practices, even if they suspect or know of their partner's extramarital relations (Blanc et al., 1996). Although HIV cannot be spread through sexual intercourse in stable monogamous relationships between uninfected partners, among married women the presence and the nature of their partners' casual or extramarital sexual practices largely determines the risk of HIV transmission (Ahlburg et al., 1997).

The level of formal schooling may influence perception of HIV risk and sexual behaviour but the evidence is rather conflicting. Caraël (1995) found increased casual sexual activity among those with higher schooling but Meekers (1994) found that the association disappears when age is controlled for.

Knowledge of AIDS has increased remarkably over the years and is almost universal in most sub-Saharan African countries but the association between such knowledge and sexual behaviour is rather ambiguous. Cleland (1995), using the World Health Organization/Global Programme on AIDS (WHO/GPA) data, did not find significant associations between levels of AIDS awareness and the number of partners and self-perceived risk. Findings by Fapohunda \& Rutenberg (1999) and Idele (2002) may provide a possible explanation for the weak link between knowledge, perceived risk and behaviour. In their studies, respondents had a fatalistic attitude towards AIDS. The expression 'after all you have to die of something' was cited to justify high-risk behaviour. This fatalism has been noted in other studies where participants are aware of modes of transmission and prevention and yet continue to engage in risky sexual practices (Obbo, 1993).

Exposure to AIDS information through mass media may lead to high levels of awareness, which can in turn influence self-assessed risk of HIV and behaviour. It has been argued that people's assessment of risk may depend upon how much they trust the accuracy of the information (Stallings, 1990). However Prohaska et al. (1990) 
found that neither increased exposure to the media and greater belief in the accuracy of the media as a source of information about AIDS nor knowledge of the facts about HIV/AIDS transmission affected people's perception of risk.

UNAIDS (2000b) notes that general awareness of AIDS is no longer important in AIDS prevention but accurate knowledge of how HIV is transmitted is important. For example if people believe that mosquitoes transmit the HIV virus, they may see the use of condoms as futile. Some researchers report that asymptomatic transmission of HIV is not common in local concepts of disease (Irwin et al., 1991; Hogsborg \& Aaby, 1992). A study of AIDS knowledge in Zimbabwe revealed that while all men and women had heard of AIDS, $15 \%$ of men and $26 \%$ of women did not believe that a healthy-looking person can carry the AIDS virus (Central Statistical Office, Zimbabwe \& Macro International, 1995). This belief can lead to exposure to HIV infection since people are unlikely to take precautions when having sexual intercourse with healthy-looking partners.

The belief that AIDS is a disease for 'high-risk' groups can influence people's perceptions and behaviour. For a long time in Kenya, AIDS was associated with homosexuals, drug users, prostitutes, truck drivers and tourists. As a result, some people discounted their own risk because they did not identify with these high-risk groups (Kenya et al., 1998; Okeyo et al., 1998). Another belief that may influence the perception of HIV is the way that illness is viewed (Williams, 1986). Some see AIDS as punishment for immoral behaviour so that those who see their lifestyle as being morally upright may perceive their chance of being infected by HIV to be low (Konde-Lule, 1993; Nzioka, 1996). Another consequence of this belief is that AIDS sufferers are stigmatized (Irwin et al. 1991; Anarfi, 1993).

\section{Data}

The data used are from the 1998 Kenya Demographic and Health Survey (KDHS). The 1998 KDHS was designed as a follow-up to the 1989 and 1993 surveys that were national in scope and targeted women and men residing in private households throughout the country. Persons residing on state land (for example national parks) and in institutions, which account for less than $1 \%$ of the total population, were not included. Sparsely populated semi-desert areas of nomadic communities in the north and north-eastern provinces of Kenya were also excluded. Together, the excluded areas account for less than $4 \%$ of Kenya's population. The survey collected information on various demographic and health indicators, including individual characteristics, marriage and sexual activity, family planning knowledge and use, and HIV/AIDS-related knowledge, attitudes and behaviour.

The KDHS used a two-stage stratified sample consisting first of selected primary sampling units (PSUs) or clusters, and secondly, selected households within PSUs. These PSUs were derived from census enumeration areas defined during the 1989 census and updated during the 1993 KDHS. Some districts were over-sampled so that reliable district-level estimates could be produced. As a consequence, the 1998 KDHS is not self-weighting at the national level.

All women of age 15-49 years were targeted for interview in the selected households. Every second household was identified for inclusion in the male survey, 
Table 1. Models fitted and variables used in the logistic regression modelling

Models

Variables in each model

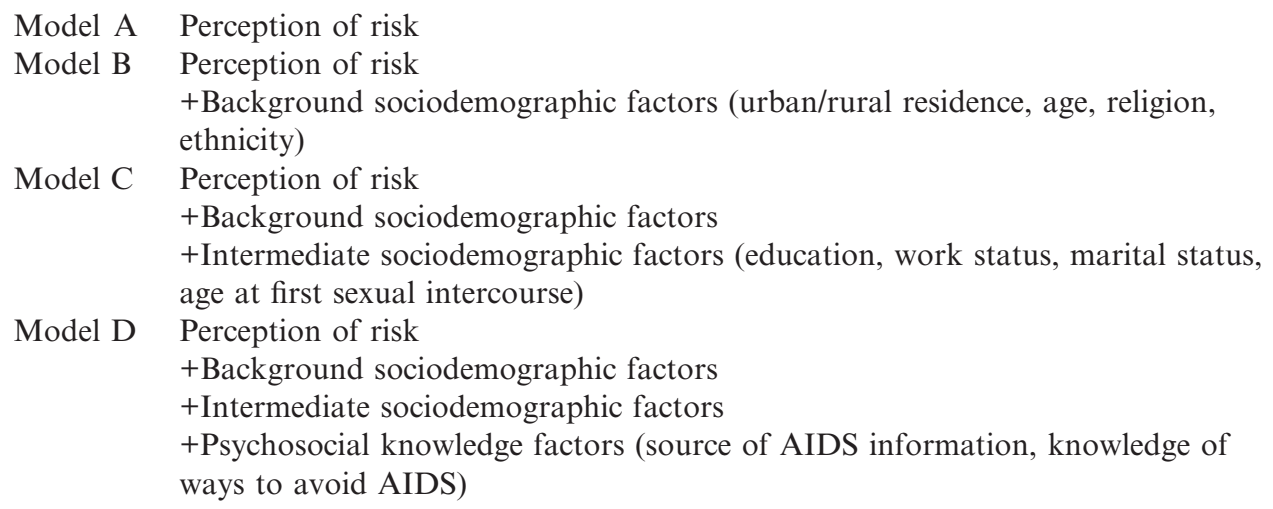

and all men aged 15-54 years were identified and considered eligible for individual interview. The analysis in this paper is based on 6569 women and 2959 men who reported having heard of HIV/AIDS, who were sexually experienced, and who responded to the question on perceptions of risk.

\section{Methods}

Many statisticians advise that complex survey designs need to be accounted for in data analysis in order to obtain unbiased point estimates and accurate confidence intervals (Smith, 1988; Skinner, Holt \& Smith, 1989; Korn \& Graubard, 1995; Eltinge, Parsons \& Jang, 1997). As the KDHS sampling used complex methods rather than simple random sampling, exploratory data analyses were carried out using survey design-based $F$-ratios (StataCorp, 2001). The statistical software STATA, version 7·0, was used for all analyses because it has a feature for estimating accurate standard errors where the sample has been drawn using clusters, stratification and unequal weights (StataCorp, 2001).

In order to examine the nature and strength of the association between perception of risk and sexual behaviour it was necessary to control for the confounding effects of other correlates of sexual behaviour using multivariate analyses. Logistic regression was used, since the dependent variable (a score of high-risk sexual behaviour) was constructed to be a binary outcome. A sequential approach was adopted, starting with a model with just perception of risk, and then adding blocks of variables in steps (Table 1). Adjusted Wald's statistics were used to measure statistical significance. Conventional measures to assess model fit, such as changes in $-2 \log$ likelihood ratio test or pseudo- $R^{2}$, are not supported by STATA when using the complex survey design estimation procedures. 
The Kenyan DHS data are hierarchical in that individuals are nested within clusters. The approach that is adopted in this paper is to control for this hierarchical structure, but not to quantify the degree of clustering. For the latter approach, multilevel models would be appropriate. However, software that fits multilevel models while accounting for the complex survey design at the same time is not publicly available (Pfeffermann et al., 1998).

\section{Definition of variables}

The dependent variable is a score derived from information on whether or not the respondent reported any risky sexual behaviour/experience in the last 12 months before the survey. The 12-month reference period is useful for capturing the most recent behaviour and minimizes recall errors. Respondents were coded ' 1 ' if they reported any type of risky sexual behaviour or experience and ' 0 ' otherwise. The risky behaviour or experiences were: reporting more than one sexual partner (while taking into account men in polygamous unions); the last sexual partner being casual or non-regular; condoms not being used during the last sexual encounter with a casual partner; and having had an STD. Unmarried women and men who reported having sexual intercourse with one regular sexual partner only were treated as not reporting risky sexual behaviour. Experience of an STD in the past 12 months was used because it is an important co-factor of HIV transmission. According to the UNAIDS and WHO guidelines, curable STDs 'are an important indicator of potential exposure to HIV infection, both because they are co-factors for infection and because they indicate unprotected sex with non-monogamous partners' (UNAIDS \& WHO, 2000, p. 18).

Since condom use is not very common among married couples or those in regular relationships in Kenya, and because of problems of interpretation (Dare \& Cleland, 1994), information on condom use was restricted to the last sexual encounter where this was with a casual partner. The age at first sex was not used to derive the risky behaviour variable because respondents had their first sexual experiences at different times of the AIDS epidemic, but it is in the explanatory part of the model.

The question on perception of risk was: 'Do you think your chances of getting AIDS are small, moderate, great, no risk at all or don't you know?' Only $0 \cdot 2 \%$ of women and $0 \cdot 1 \%$ of men gave the 'don't know' response and these were combined with the 'small risk' group. Therefore, four levels of self-assessed risk are used in the multivariate analysis: 'no risk', 'small risk', 'moderate risk' and 'great risk'.

The source of AIDS information variable had two categories: a mix of formal and non-formal, and only formal. The sources considered formal are radio, television, newspapers, posters/pamphlets and clinic/health workers. These are sources used for public AIDS awareness and prevention campaigns in Kenya and are considered less likely to be influenced by personal biases and beliefs. The sources categorized as non-formal include churches, schools and teachers, community meetings, friends and relatives, and the work-place. These sources are prone to personal biases and may contain both correct and incorrect information.

A series of questions on knowledge of the ways in which AIDS can be transmitted was used to form a three-category variable coded as 'low' if a respondent gave up to 
Table 2. Percentage of AIDS-aware, sexually experienced women and men reporting risky sexual behaviour in the last 12 months

\begin{tabular}{lrr}
\hline Type of behaviour & Women & Men \\
\hline Had multiple partners & $3 \cdot 5$ & $42 \cdot 8$ \\
Had sex with casual partner & $4 \cdot 0$ & $16 \cdot 9$ \\
Married, had casual sexual partner & $1 \cdot 1$ & $9 \cdot 7$ \\
Had sexually transmitted disease & $2 \cdot 0$ & $4 \cdot 8$ \\
Married, last casual sex without condoms & $0 \cdot 9$ & $4 \cdot 5$ \\
Unmarried, no regular partner but had sex & $3 \cdot 7$ & $5 \cdot 6$ \\
Unmarried, no regular partner and last sex without condoms & $3 \cdot 2$ & $3 \cdot 4$ \\
Overall & $11 \cdot 1$ & $44 \cdot 7$ \\
\hline
\end{tabular}

Note: These categories are not mutually exclusive. There is no double counting as respondents are coded as ' 1 ', i.e. reporting risky behaviour, if they report any of these.

three correct answers out of a possible eight; 'moderate' if he or she gave four or five correct answers; and 'high' if he or she gave six or more correct answers.

An index of the level of household wealth was created based on possession of modern amenities (electricity, flush toilet, television, refrigerator, radio, motorcycle, car and modern roof).

Survey data on sexual behaviour have been criticized as being potentially inaccurate (Caldwell, Caldwell \& Quiggin, 1989). However, Dare \& Cleland (1994) argue that similar sentiments were expressed regarding fertility and family planning data and these proved to be overstated. It is also argued that women under-state their levels of risky sexual behaviour, while men over-state theirs (Family Health International, 1999; Reid, 1999). To avoid distortion of the results as a result of reporting biases, separate analyses are conducted for men and women. Thus although the comparison of the levels of risky sexual behaviour between men and women may be distorted, the associations between sexual behaviour with other variables may be preserved.

\section{Results}

\section{Descriptive results}

In general, higher proportions of men than women reported risky sexual behaviour (Table 2). About $45 \%$ of men and $11 \%$ of women reported to have been engaged in risky sexual behaviour in the 12 months before the 1998 KDHS. The most commonly reported risky sexual behaviour by men was having multiple partners and for women it was having a casual partner.

Overall, $28 \%$ of women and $27 \%$ of men in Kenya perceived themselves to be at no risk at all from HIV infection. About $49 \%$ of women and $34 \%$ of men perceived their risks to be small while only $5 \%$ of men and $10 \%$ of women perceived their risk 


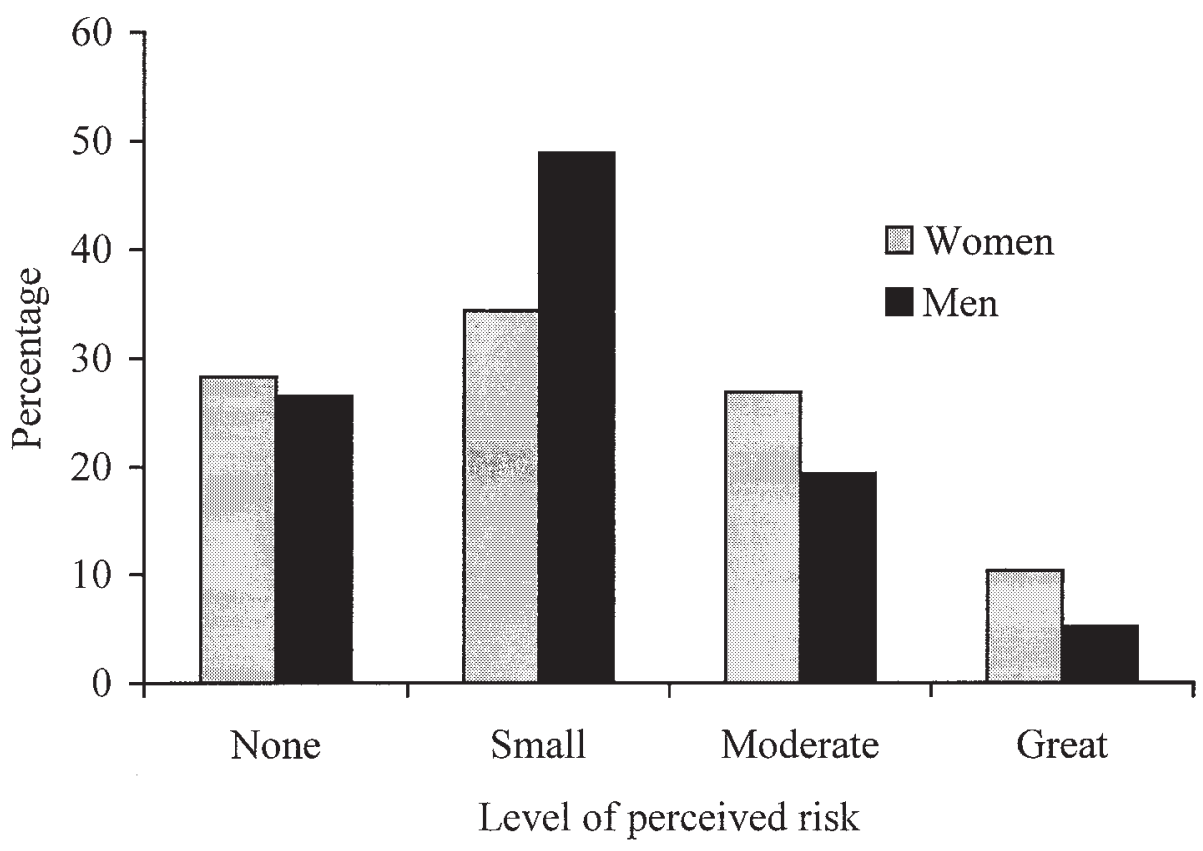

Fig. 2. Percentages of women and men perceiving different levels of risk of contracting AIDS, KDHS 1998.

of HIV infection to be great (Fig. 2). The respondents were asked to provide reasons for their perceptions of risk. The majority cited having one partner as a reason for perceiving their risk of HIV infection to be small or nil $(57 \%$ of women and $53 \%$ of men). More men (19\%) than women (3\%) cited condom use as a reason for small or no risk. Most women (63\%) who perceived their risk of HIV infection to be moderate or great gave the reason that they suspected that their spouse/partner had other sexual partners. Only $23 \%$ of the men reported the same. About $46 \%$ of men reported their risk as moderate or high because they had many sex partners, hence almost corroborating women's fears of their spouse/partner's multiple sexual relations. Fewer than one in five men and women perceived themselves at high risk because of not using condoms.

The bivariate analysis of the association between risky sexual behaviour and background and intermediate sociodemographic factors (Table 3) shows that region of residence, work status, education, ethnicity, age and marital status were associated with reporting of risky sexual behaviour for both women and men at the $5 \%$ level of significance. Religion was not significant for either females or males.

The percentages of men and women who reported risky sexual behaviour but who perceived themselves to be at small or no risk of HIV infection were analysed. These men and women were singled out because they appear to under-rate their risk of HIV in relation to their reported sexual behaviour. The results show clearly that young, unmarried (or formerly married) persons appear to under-rate their risk despite engaging in risky sexual behaviour (Table 4). 
Multivariate logistic regression results

Tables 5 and 6 give the results of the female and male logistic regression models fitted to examine the association between perception of risk and risky sexual behaviour while controlling for other correlates of sexual behaviour. Since region of residence was highly correlated with ethnicity, only the latter was used in the multivariate analysis. No interaction effects were statistically significant at conventional levels.

Females. The unadjusted association between perception of risk and risky sexual behaviour for females is presented in Model A, Table 5. There was no significant difference in the odds of reporting risky sexual behaviour between those who perceived their risk to be small and those who perceived no risk at all. However, the odds of reporting risky sexual behaviour among those who perceived their risk to be moderate or great are significantly larger than the odds for those who perceive no risk.

The introduction of background sociodemographic factors such as age, ethnicity, religion and urban or rural residence did not change the direction of the association between perception of risk and reported risky sexual behaviour but rather, the association became stronger (see Model B). Age and ethnicity (and, marginally, urban or rural residence) were significantly associated with risky sexual behaviour at the $5 \%$ level.

In Model C, intermediate sociodemographic factors such as marital status and the level of household wealth were significant, while the age at first sexual intercourse, the level of education and work status were not. Inclusion of these variables did not attenuate the association between perception of risk and risky sexual behaviour. The association between age and risky sexual behaviour became weaker after the inclusion of the variable on marital status. The knowledge factors (source of AIDS information and knowledge of ways of AIDS transmission) were not significant and consequently Models $\mathrm{C}$ and $\mathrm{D}$ are almost identical. The interpretation below is based on the odds ratios (ORs) from Model D.

The association between perception of risk and self-reported risky sexual behaviour is such that those who perceive their risk of HIV infection to be great were more likely to have engaged in risky sexual behaviour. The odds of reporting risky sexual behaviour for such women were more than 2.5 times the odds of those who perceived themselves to be at no risk of HIV infection. Women aged 25-39 years were less likely to report risky behaviour compared with women aged 15-19 years $(\mathrm{OR}=0 \cdot 70)$ and women aged 40 or older had the lowest odds $(\mathrm{OR}=0 \cdot 51)$.

Ethnic differences in reporting of risky sexual behaviour are observed. The Luo, Meru and Embu ethnic groups have significantly higher odds of reporting risky sexual behaviour than the Kalenjin. Marital status has a very strong association with reporting of risky sexual behaviour. Persons who were not married at the time of the survey had the highest odds of reporting risky sexual behaviour compared with those married monogamously $(\mathrm{OR}=18 \cdot 2$ for formerly married women and $13 \cdot 1$ for never-married women).

Women with medium or high levels of household wealth (measured by the presence of modern amenities such as electricity, radio, motorcar and other items) had 
Table 3. Percentages of AIDS-aware, sexually experienced women and men reporting any risky sexual behaviour in the last 12 months by background characteristics, KDHS 1998

\begin{tabular}{|c|c|c|c|c|}
\hline \multirow[b]{2}{*}{ Characteristics } & \multicolumn{2}{|c|}{ Women } & \multicolumn{2}{|c|}{ Men } \\
\hline & $\%$ & No. of cases & $\%$ & No. of cases \\
\hline Region & $* * *$ & & $*$ & \\
\hline Rift Valley & $9 \cdot 5$ & 1423 & $41 \cdot 0$ & 673 \\
\hline Central & $6 \cdot 6$ & 716 & $25 \cdot 9$ & 288 \\
\hline Coast & $8 \cdot 2$ & 496 & $51 \cdot 7$ & 214 \\
\hline Eastern & $13 \cdot 6$ & 1128 & $45 \cdot 9$ & 540 \\
\hline Nyanza & $13 \cdot 9$ & 1420 & $50 \cdot 0$ & 563 \\
\hline Western & $10 \cdot 5$ & 740 & $42 \cdot 4$ & 275 \\
\hline Nairobi & $12 \cdot 3$ & 645 & $39 \cdot 2$ & 405 \\
\hline Residence & $* *$ & & $*$ & \\
\hline Urban & $14 \cdot 1$ & 1555 & $40 \cdot 7$ & 841 \\
\hline Rural & $10 \cdot 2$ & 5014 & $46 \cdot 3$ & 2118 \\
\hline Education & $*$ & & $* * *$ & \\
\hline No education & $8 \cdot 8$ & 842 & $27 \cdot 4$ & 119 \\
\hline Primary & $12 \cdot 1$ & 3843 & $48 \cdot 2$ & 1560 \\
\hline Secondary and above & $10 \cdot 2$ & 1884 & $42 \cdot 1$ & 1280 \\
\hline Work status & $*$ & & $* * *$ & \\
\hline No & $12 \cdot 5$ & 2738 & $66 \cdot 2$ & 795 \\
\hline Yes & $10 \cdot 1$ & 3830 & $36 \cdot 9$ & 2165 \\
\hline Household wealth & $* * *$ & & & \\
\hline Low & $14 \cdot 2$ & 1671 & $46 \cdot 1$ & 680 \\
\hline Medium & $9 \cdot 8$ & 3783 & $46 \cdot 0$ & 1717 \\
\hline High & $10 \cdot 7$ & 1114 & $39 \cdot 8$ & 562 \\
\hline \multicolumn{5}{|l|}{ Religion } \\
\hline Protestant & $11 \cdot 4$ & 4233 & $44 \cdot 5$ & 1713 \\
\hline Catholic & $10 \cdot 7$ & 1829 & $45 \cdot 7$ & 903 \\
\hline Other & $10 \cdot 5$ & 507 & $43 \cdot 3$ & 342 \\
\hline Ethnicity & $* *$ & & $* * *$ & \\
\hline Kalenjin & $8 \cdot 7$ & 818 & $36 \cdot 9$ & 347 \\
\hline Kamba & $11 \cdot 8$ & 811 & $46 \cdot 6$ & 374 \\
\hline Kikuyu & $9 \cdot 0$ & 1216 & $45 \cdot 0$ & 558 \\
\hline Kisii & $11 \cdot 5$ & 656 & $44 \cdot 9$ & 305 \\
\hline Luhya & $10 \cdot 8$ & 957 & $42 \cdot 3$ & 415 \\
\hline Luo & $15 \cdot 2$ & 976 & $51 \cdot 0$ & 392 \\
\hline Meru/Embu & $15 \cdot 4$ & 476 & $50 \cdot 5$ & 256 \\
\hline Mijikenda/Swahili/Taita & $8 \cdot 1$ & 382 & $51 \cdot 6$ & 148 \\
\hline Others & $8 \cdot 3$ & 276 & $31 \cdot 6$ & 164 \\
\hline Age & $* * *$ & & $* * *$ & \\
\hline $15-19$ & $25 \cdot 1$ & 799 & $83 \cdot 2$ & 439 \\
\hline $20-24$ & $12 \cdot 7$ & 1365 & $76 \cdot 5$ & 533 \\
\hline $25-39$ & $8 \cdot 3$ & 3285 & $35 \cdot 3$ & 1241 \\
\hline $40-49$ (40-54 for men) & $7 \cdot 5$ & 1120 & $15 \cdot 0$ & 747 \\
\hline
\end{tabular}


Table 3. (Continued)

\begin{tabular}{|c|c|c|c|c|}
\hline \multirow[b]{2}{*}{ Characteristics } & \multicolumn{2}{|c|}{ Women } & \multicolumn{2}{|r|}{ Men } \\
\hline & $\%$ & No. of cases & $\%$ & No. of cases \\
\hline Marital status & $* * *$ & & $* * *$ & \\
\hline Never married & $31 \cdot 5$ & 1127 & $84 \cdot 6$ & 1052 \\
\hline Married (monogamous) & $3 \cdot 0$ & 4022 & $18 \cdot 7$ & 1609 \\
\hline Married (polygynous) & $5 \cdot 8$ & 754 & $19 \cdot 4$ & 173 \\
\hline Formerly married & $32 \cdot 0$ & 665 & $79 \cdot 0$ & 126 \\
\hline Age at first sex & & & $* * *$ & \\
\hline 15 or older & $10 \cdot 6$ & 4601 & $39 \cdot 2$ & 1869 \\
\hline$<15$ years & $12 \cdot 7$ & 1689 & $56 \cdot 5$ & 964 \\
\hline Don't know/missing & $9 \cdot 6$ & 279 & $37 \cdot 5$ & 131 \\
\hline Perception of HIV risk & $* * *$ & & $* * *$ & \\
\hline None & $9 \cdot 3$ & 1858 & $36 \cdot 3$ & 783 \\
\hline Small & $9 \cdot 9$ & 2260 & $45 \cdot 1$ & 1446 \\
\hline Moderate & $12 \cdot 4$ & 1765 & $53 \cdot 1$ & 575 \\
\hline Great & $16 \cdot 8$ & 686 & $53 \cdot 0$ & 155 \\
\hline \multicolumn{5}{|l|}{ Source of AIDS information } \\
\hline Formal only & $11 \cdot 6$ & 4792 & $44 \cdot 7$ & 1638 \\
\hline Mixed & $9 \cdot 8$ & 1776 & $44 \cdot 7$ & 1321 \\
\hline \multicolumn{5}{|c|}{ Knowledge of AIDS transmission } \\
\hline Low & $10 \cdot 6$ & 2863 & $45 \cdot 2$ & 1166 \\
\hline Medium & $11 \cdot 5$ & 3461 & $45 \cdot 1$ & 1679 \\
\hline High & $12 \cdot 3$ & 245 & $35 \cdot 1$ & 114 \\
\hline Total women & $11 \cdot 1$ & 6569 & $44 \cdot 7$ & 2959 \\
\hline
\end{tabular}

$* 0 \cdot 01<p<0 \cdot 05$ for design-based $F$-ratio; $* * 0 \cdot 001<p<0 \cdot 01 ; * * * p<0 \cdot 001$.

significantly lower odds of reporting risky sexual behaviour than women from households with low wealth. No significant association was observed between source of AIDS information or knowledge of the ways AIDS is transmitted and sexual behaviour.

Males. The association between perception of risk and sexual behaviour among males (Table 6) is highly significant, and stronger than for the female sample. The inclusion of the background sociodemographic factors in Model B did not change the association between perception of risk and risky behaviour. Rather, the odds ratios increased, suggesting a stronger association. The age of the respondent, ethnicity and urban or rural residence were significant at the 5\% level.

In Model $\mathrm{C}$, intermediate sociodemographic factors were included, and of these, the age at first sexual intercourse and marital status were significant, and education marginally significant, at the 5\% level. The source of AIDS information and knowledge of the ways in which AIDS is transmitted were not significant (Model D). A fifth model (results not shown) excluded the perception of risk variable and this did 
Table 4. Percentages of AIDS-aware, sexually experienced women and men who reported risky sexual behaviour but who perceived little or no risk of HIV infection, KDHS 1998

\begin{tabular}{|c|c|c|c|c|}
\hline \multirow[t]{2}{*}{ Characteristic } & \multicolumn{2}{|c|}{ Women } & \multicolumn{2}{|c|}{ Men } \\
\hline & $\%$ & $n$ & $\%$ & $n$ \\
\hline \multicolumn{5}{|l|}{ Age } \\
\hline $15-19$ & $16 \cdot 6$ & 799 & $62 \cdot 4$ & 439 \\
\hline $20-24$ & $6 \cdot 8$ & 1365 & $54 \cdot 4$ & 533 \\
\hline $25-39$ & $3 \cdot 6$ & 3285 & $24 \cdot 1$ & 1240 \\
\hline $40-49(54)$ & $4 \cdot 8$ & 1120 & $9 \cdot 8$ & 746 \\
\hline \multicolumn{5}{|l|}{ Marital status } \\
\hline Never married & $18 \cdot 5$ & 1127 & $61 \cdot 9$ & 1052 \\
\hline Married (monogamous) & $1 \cdot 1$ & 4022 & $11 \cdot 9$ & 1609 \\
\hline Married (polygamous) & $2 \cdot 0$ & 754 & $11 \cdot 6$ & 173 \\
\hline Formerly married & $19 \cdot 4$ & 665 & $57 \cdot 9$ & 126 \\
\hline All women & $6 \cdot 9$ & 6569 & $31 \cdot 6$ & 2959 \\
\hline
\end{tabular}

not alter the results for the other variables. Thus, the results of Model D are used to interpret the male results.

The association between perception of risk and reporting of risky sexual behaviour is stronger for Kenyan men than for women. Men who perceived themselves to be at 'low risk' had about double the odds of those who perceived themselves to be at 'no risk'; those who perceived 'moderate to great risk' had more than three times the odds of reporting risky sexual behaviour. The association of risky sexual behaviour and age for men is similar to that for women, showing lower odds for older men aged 40-54.

Ethnic differences were highly significant. With the exception of the Kisii, the rest of the ethnic groups had about $20 \%$ to $150 \%$ higher odds of reporting risky sexual encounters compared with Kalenjin men. The highest likelihood of reporting risky behaviour was among Mijikenda, Swahili or Taita-Taveta men; in the models for women, these ethnic groups had the lowest odds. Formerly and never-married men were much more likely to have engaged in risky sexual behaviour than married men. A significant association between the age at first sexual intercourse and reporting of risky sexual behaviour was observed among men. Those who had their first sexual intercourse before the age of 15 years had about 50\% higher odds of reporting risky behaviour compared with those who had first sex at 15 years or older age. The level of education, household wealth, the source of AIDS information and knowledge of ways in which AIDS is transmitted were not significant.

\section{Discussion}

This paper set out to examine the association between self-perceived risk of HIV infection and risky sexual behaviour among Kenyan women and men. The results 
indicate some differences between women and men in their experiences of risky sexual behaviour and self-perceived risk. Among the KDHS respondents who were sexually experienced and aware of AIDS, about $45 \%$ of men compared with $11 \%$ of women reported high-risk sexual behaviour in the last 12 months.

This study assumed that background factors at national, community and individual levels operate through a range of intermediate sociodemographic and psychosocial factors to influence perception of HIV risk and sexual behaviour. However, the inclusion of the sociodemographic and psychosocial factors in the models did not attenuate the positive association between risk perception and sexual behaviour, suggesting that an independent association exists between these two variables within sub-groups of men and women of different demographic and social profiles.

The positive association between perceived risk and risky sexual behaviour for both women and men is consistent with findings from previous studies in sub-Saharan Africa. Cleland (1995) and Ingham \& Holmes (1991) also found similar positive associations between perceptions of risk and risky sexual behaviour using data from the WHO/GPA survey. Since the $1998 \mathrm{KDHS}$ is cross-sectional, it is difficult to say whether perception of risk is based on previous sexual behaviour or whether behaviour is based on perception. A qualitative study that complemented this analysis indicated that feelings of personal vulnerability are very subjective and vary by context and time (Idele, 2002). Thus, sexual behaviour is more likely to be based upon subjective perceptions of risk rather than actual risk. Similarly, previous research in Kenya and elsewhere (Bauni \& Jarabi, 2000; Nzioka, 1996; Ingham, Woodcock \& Stenner, 1992) suggests that individuals, particularly young people, often feel invulnerable to HIV infection. AIDS is seen as a distant rather than an immediate threat: a disease that affects other people.

The results show that young men and women and those who are not married are more likely to report risky sexual behaviour than older, married men and women. Previous studies in Kenya have recorded similar results (Kiragu \& Zabin, 1995; Ajayi et al., 1991; Ocholla-Ayayo \& Schwarz, 1991). In Kenya, most men and women eventually marry, so there is a strong link between age and marital status. The median age at first sexual intercourse in Kenya is currently estimated at 17 years for both males and females and the median age at first marriage is estimated at 20 years for females and 25 years for males (National Council for Population and Development et al., 1999). A difference in the median age at first sexual intercourse and first marriage implies that there is some span of time spent in experimental, non-marital sexual relations. Such relations are likely to be with casual partners in unstable relationships.

Marriage provides checks and balances on individuals' sexual behaviour. Societal norms in Africa expect faithfulness in marriage, particularly for women, with severe consequences in cases of infidelity. Conversely, marriage dissolution creates new freedoms away from marital obligations, hence the increased chances of formerly married women and men engaging in risk-taking behaviour. However, multiple partners for men are easily tolerated (Fapohunda \& Rutenberg, 1999; Caldwell et al., 1993). It has been suggested that African societies are more tolerant of men's infidelity because of the practice of postpartum sexual abstinence (Ocholla-Ayayo \& Schwartz, 
Table 5. Odds ratios for reporting of risky sexual behaviour in the last 12 months among AIDS-aware, sexually experienced women, KDHS 1998

\begin{tabular}{|c|c|c|c|c|}
\hline Covariate and category & Model A & Model B & Model C & Model D \\
\hline \multicolumn{5}{|l|}{ Perception of risk } \\
\hline None & $1 \cdot 00$ & $1 \cdot 00$ & $1 \cdot 00$ & $1 \cdot 00$ \\
\hline Small & $1 \cdot 06$ & $1 \cdot 16$ & $1 \cdot 20$ & $1 \cdot 20$ \\
\hline Moderate & $1 \cdot 38 * *$ & $1 \cdot 56^{* *}$ & $1 \cdot 84 * * *$ & $1 \cdot 82 * * *$ \\
\hline Great & $1.97 * * *$ & $2 \cdot 08 * * *$ & $2 \cdot 65 * * *$ & $2 \cdot 63 * * *$ \\
\hline \multicolumn{5}{|l|}{ Sociodemographic (background) } \\
\hline \multicolumn{5}{|l|}{ Age } \\
\hline $15-19$ & - & $1 \cdot 00$ & $1 \cdot 00$ & $1 \cdot 00$ \\
\hline $20-24$ & - & $0 \cdot 42 * * *$ & $0 \cdot 90$ & $0 \cdot 89$ \\
\hline $25-39$ & - & $0 \cdot 26 * * *$ & $0 \cdot 71$ & $0 \cdot 70^{*}$ \\
\hline $40-49$ & - & $0 \cdot 25 * * *$ & $0 \cdot 51^{* *}$ & $0 \cdot 51^{* *}$ \\
\hline \multicolumn{5}{|l|}{ Ethnicity } \\
\hline Kalenjin & - & $1 \cdot 00$ & $1 \cdot 00$ & $1 \cdot 00$ \\
\hline Kamba & - & $1 \cdot 40$ & $1 \cdot 33$ & $1 \cdot 33$ \\
\hline Kikuyu & - & $1 \cdot 02$ & $0 \cdot 92$ & $0 \cdot 91$ \\
\hline Kisii & - & $1 \cdot 18$ & $1 \cdot 14$ & $1 \cdot 13$ \\
\hline Luhya & - & $1 \cdot 11$ & $1 \cdot 27$ & $1 \cdot 27$ \\
\hline Luo & - & $1 \cdot 48$ & $1 \cdot 70^{* *}$ & $1 \cdot 69 * *$ \\
\hline Meru/Embu & - & $1 \cdot 87 * *$ & $2 \cdot 16^{* * *}$ & $2 \cdot 11 * * *$ \\
\hline Mijikenda/Swahili/Taita-Taveta & - & $0 \cdot 76$ & 0.74 & 0.73 \\
\hline Others & - & $0 \cdot 84$ & $0 \cdot 91$ & $0 \cdot 90$ \\
\hline \multicolumn{5}{|l|}{ Religion } \\
\hline Protestant & - & $1 \cdot 00$ & $1 \cdot 00$ & $1 \cdot 00$ \\
\hline Catholic & - & $0 \cdot 90$ & $0 \cdot 85$ & $0 \cdot 85$ \\
\hline Other & - & $1 \cdot 22$ & $1 \cdot 13$ & $1 \cdot 13$ \\
\hline \multicolumn{5}{|l|}{ Type of place of residence } \\
\hline Rural & - & $1 \cdot 00$ & $1 \cdot 00$ & $1 \cdot 00$ \\
\hline Urban & & $1 \cdot 33^{*}$ & $1 \cdot 29$ & $1 \cdot 29$ \\
\hline \multicolumn{5}{|l|}{ Sociodemographic (intermediate) } \\
\hline \multicolumn{5}{|l|}{ Educational level } \\
\hline Primary & - & - & $1 \cdot 00$ & $1 \cdot 00$ \\
\hline Secondary or higher & - & - & $0 \cdot 84$ & $0 \cdot 83$ \\
\hline None & - & - & $0 \cdot 85$ & $0 \cdot 86$ \\
\hline \multicolumn{5}{|l|}{ Work status } \\
\hline Working & - & - & $1 \cdot 00$ & $1 \cdot 00$ \\
\hline Not working & & & $1 \cdot 15$ & $1 \cdot 15$ \\
\hline \multicolumn{5}{|l|}{ Household wealth } \\
\hline Low & - & - & $1 \cdot 00$ & $1 \cdot 00$ \\
\hline Medium & - & - & $0.76^{*}$ & $0 \cdot 76^{*}$ \\
\hline High & - & - & $0 \cdot 61^{* *}$ & $0 \cdot 61 * *$ \\
\hline
\end{tabular}


Table 5. (Continued)

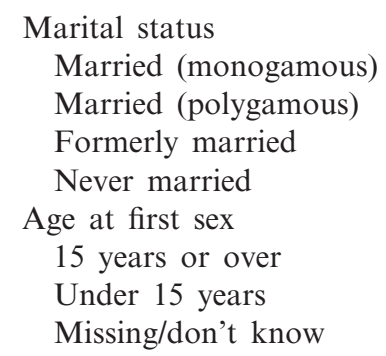

$\begin{array}{llll}- & - & 1 \cdot 00 & 1 \cdot 00 \\ - & - & 1 \cdot 74^{*} & 1 \cdot 74^{*} \\ - & - & 18 \cdot 25^{* * *} & 18 \cdot 24^{* * *} \\ - & - & 13 \cdot 21^{* * *} & 13 \cdot 14^{* * *} \\ & & & \\ - & - & 1.00 & 1.00 \\ - & - & 1.07 & 1.08 \\ - & - & 1.43 & 1.44\end{array}$

\section{Knowledge factors}

Source of AIDS information

Mix of formal and non-formal

Formal only

Knowledge of mechanisms of AIDS transmission

Low

Moderate

High

$\begin{array}{llll}- & - & - & 1.00 \\ - & - & - & 0.97 \\ - & - & - & 1.00 \\ - & - & - & 1.08 \\ - & - & - & 1.19\end{array}$

$* 0 \cdot 01<p<0 \cdot 05$ for adjusted Wald's test; ${ }^{* *} 0 \cdot 001<p<0 \cdot 01 ; * * * p<0 \cdot 001$.

For description of Models A to D, see Table 1.

1991). Generally, postpartum abstinence is imposed on the women and higher levels of male extramarital sexual activity are observed. Ali \& Cleland (2001), using DHS data from Cotê d'Ivoire, found that extramarital sexual intercourse was twice as common among married men who were practising postpartum sexual abstinence than other men. In Kenya, the period of postpartum abstinence is short, ranging from two to four months. Central region, which has the lowest level of reported risky sexual behaviour, also has the lowest median duration of postpartum sexual abstinence.

Ethnicity and region of residence are closely linked in Kenya, thus it is not surprising that region of residence is insignificant in the models once ethnicity is controlled for. Specific ethnic groups with almost similar cultural practices live in proximity to each other within regions. The Luo and Kisii, for example, largely inhabit Nyanza Province, while the Luhya mostly reside in Western Province. The Kalenjin ethnic group predominates in Rift Valley Province. As noted earlier in this paper, HIV prevalence rates in Kenya are more pronounced in Nyanza, Nairobi and parts of Western and Rift Valley Provinces, where observed sentinel surveillance HIV prevalence rates among pregnant women range from $15 \%$ to $30 \%$, and AIDS morbidity and mortality are high (Government of Kenya/AIDS Control Unit et al., 2001; Baltazar et al., 1999). High proportions of women and men in these regions perceived themselves to be at risk of HIV. Some authors have suggested that perceived risk may not only be based on a person's own behaviour, or that of his or her partner, but also on the level of AIDS-related morbidity and mortality within the 
Table 6. Odds ratios for reporting of risky sexual behaviour in the last 12 months among AIDS-aware, sexually experienced men, KDHS 1998

\begin{tabular}{|c|c|c|c|c|}
\hline Covariate and category & Model A & Model B & Model C & Model D \\
\hline \multicolumn{5}{|l|}{ Perception of risk } \\
\hline None & $1 \cdot 00$ & $1 \cdot 00$ & $1 \cdot 00$ & $1 \cdot 00$ \\
\hline Small & $1 \cdot 44 * * *$ & $1 \cdot 84 * * *$ & $2 \cdot 00 * * *$ & $2 \cdot 01 * * *$ \\
\hline Moderate & $1.99 * * *$ & $2 \cdot 77 * * *$ & $3 \cdot 22 * * *$ & $3 \cdot 28 * * *$ \\
\hline Great & $1.98 * * *$ & $2 \cdot 99 * * *$ & $3 \cdot 50 * * *$ & $3 \cdot 58 * * *$ \\
\hline \multicolumn{5}{|l|}{ Sociodemographic (background) } \\
\hline \multicolumn{5}{|l|}{ Age } \\
\hline $15-19$ & - & $1 \cdot 00$ & $1 \cdot 00$ & $1 \cdot 00$ \\
\hline $20-24$ & - & $0 \cdot 65^{*}$ & $1 \cdot 31$ & $1 \cdot 29$ \\
\hline $25-39$ & - & $0 \cdot 10^{* * *}$ & $1 \cdot 03$ & $1 \cdot 02$ \\
\hline $40-54$ & - & $0 \cdot 03 * * *$ & $0 \cdot 43^{* *}$ & $0 \cdot 43^{* *}$ \\
\hline \multicolumn{5}{|l|}{ Ethnicity } \\
\hline Kalenjin & - & $1 \cdot 00$ & $1 \cdot 00$ & $1 \cdot 00$ \\
\hline Kamba & - & $2 \cdot 13 * * *$ & $1 \cdot 68^{*}$ & $1 \cdot 73^{* *}$ \\
\hline Kikuyu & - & $1 \cdot 65 * *$ & $1 \cdot 48$ & $1 \cdot 53^{*}$ \\
\hline Kisii & - & $1 \cdot 20$ & 0.99 & $0 \cdot 97$ \\
\hline Luhya & - & $1 \cdot 76^{* *}$ & $2 \cdot 15^{* * *}$ & $2 \cdot 20 * * *$ \\
\hline Luo & - & $1 \cdot 92 * *$ & $2 \cdot 25 * * *$ & $2 \cdot 30 * * *$ \\
\hline Meru/Embu & - & $2 \cdot 34 * * *$ & $2 \cdot 07 * *$ & $2 \cdot 14^{* *}$ \\
\hline Mijikenda/Swahili/Taita-Taveta & - & $2 \cdot 65^{* * *}$ & $2 \cdot 56^{* * *}$ & $2 \cdot 52 * * *$ \\
\hline Others & - & $1 \cdot 38$ & $1 \cdot 21$ & $1 \cdot 20$ \\
\hline \multicolumn{5}{|l|}{ Religion } \\
\hline Protestant & - & $1 \cdot 00$ & $1 \cdot 00$ & $1 \cdot 00$ \\
\hline Catholic & - & $1 \cdot 15$ & $1 \cdot 10$ & $1 \cdot 11$ \\
\hline Other & - & $1 \cdot 29$ & $1 \cdot 38$ & $1 \cdot 40$ \\
\hline \multicolumn{5}{|l|}{ Type of place of residence } \\
\hline Rural & - & $1 \cdot 00$ & $1 \cdot 00$ & $1 \cdot 00$ \\
\hline Urban & & $0 \cdot 79 *$ & $0 \cdot 81$ & $0 \cdot 79$ \\
\hline \multicolumn{5}{|l|}{ Sociodemographic (intermediate) } \\
\hline \multicolumn{5}{|l|}{ Educational level } \\
\hline Primary & - & - & $1 \cdot 00$ & $1 \cdot 00$ \\
\hline Secondary or higher & - & - & $0 \cdot 78^{*}$ & $0 \cdot 79$ \\
\hline None & - & - & $0 \cdot 87$ & $0 \cdot 88$ \\
\hline \multicolumn{5}{|l|}{ Work status } \\
\hline Working & - & - & $1 \cdot 00$ & $1 \cdot 00$ \\
\hline Not working & - & - & $0 \cdot 76$ & $0 \cdot 75$ \\
\hline \multicolumn{5}{|l|}{ Household wealth } \\
\hline Low & - & - & $1 \cdot 00$ & $1 \cdot 00$ \\
\hline Medium & - & - & $0 \cdot 95$ & $0 \cdot 94$ \\
\hline High & - & - & $0 \cdot 82$ & $0 \cdot 81$ \\
\hline
\end{tabular}


Table 6. (Continued)

\begin{tabular}{|c|c|c|c|c|}
\hline \multicolumn{5}{|l|}{ Marital status } \\
\hline Married (monogamous) & - & - & $1 \cdot 00$ & $1 \cdot 00$ \\
\hline Married (polygamous) & - & - & $1 \cdot 13$ & $1 \cdot 10$ \\
\hline Formerly married & - & - & $15 \cdot 76^{* * *}$ & $15 \cdot 93 * * *$ \\
\hline Never married & - & - & $23 \cdot 73 * * *$ & $24 \cdot 17 * * *$ \\
\hline \multicolumn{5}{|l|}{ Age at first sex } \\
\hline 15 years or over & - & - & $1 \cdot 00$ & $1 \cdot 00$ \\
\hline Under 15 years & - & - & $1 \cdot 48^{* *}$ & $1 \cdot 49^{* *}$ \\
\hline Missing/don't know & - & - & $1 \cdot 19$ & $1 \cdot 19$ \\
\hline \multicolumn{5}{|l|}{ Knowledge factors } \\
\hline \multicolumn{5}{|l|}{ Source of AIDS information } \\
\hline Mix of formal and non-formal & - & - & - & $1 \cdot 00$ \\
\hline Formal only & - & - & - & $1 \cdot 24$ \\
\hline \multicolumn{5}{|c|}{ Knowledge of mechanisms of AIDS transmission } \\
\hline Low & - & - & - & $1 \cdot 00$ \\
\hline Moderate & - & - & - & $0 \cdot 99$ \\
\hline High & - & - & - & $0 \cdot 75$ \\
\hline
\end{tabular}

$* 0 \cdot 01<p<0 \cdot 05$ for adjusted Wald's test; ${ }^{* *} 0 \cdot 001<p<0 \cdot 01 ; * * * p<0 \cdot 001$.

For description of Models A to D, see Table 1.

wider community (Dodoo, 1998; Cleland, 1995; Prohaska et al., 1990). Thus, knowing of someone who has died from AIDS or experiencing an AIDS-related death in the family might increase people's fears and uncertainties.

There is also great heterogeneity with regard to culture and tradition among the various ethnic groups in Kenya. The sociocultural context can influence people's perceptions through internalization of specific sexual beliefs, norms and practices. In Nyanza and parts of Western Province the practice of widow inheritance, polygyny, a belief in witchcraft and chira (a Luo term for a body-wasting illness that is believed to afflict people who break cultural taboos), are entrenched components of the Luo and Luyha culture which have been associated with the rapid spread of AIDS (Kenya et al., 1998; Ocholla-Ayayo, 1976). Such practices and beliefs, although they may increase the risk of HIV infection, may not necessarily lead to increased perception of HIV risk if these practices are deemed to be necessary for social support, a feeling of belonging and emotional well-being of individuals and families.

Another traditional practice is that of male circumcision. Among some ethnic groups such as the Kisii and Masai, male and female circumcision are almost universal (National Council for Population and Development et al., 1999). Circumcision does not appear to have a strong association with sexual behaviour. However, a link has been observed with lower levels of HIV infection in Kenya (Auvert et al., 2001). The use of non-sterile equipment is often an undesirable feature of male circumcision and may contribute to the spread of HIV. However, there are 
indications that many groups are having the procedure conducted in modern hospital environments (Price, 1995).

These results do not show strong evidence of an association between sexual behaviour and the level of education, supporting the findings of Meekers (1994). The significance and direction of the effect of household wealth in the models for females suggests that some casual sexual relations may be engaged in for economic reasons. The insignificance of the source of AIDS information and knowledge of ways of AIDS transmission confirms the conclusions by other researchers that the source of knowledge is not a very good predictor of behaviour and perception of risk (Prohaska et al., 1990).

The link between condom use, perception of risk and sexual behaviour is not easy to assess because of the difficulty in interpreting survey responses on condom use. However, condom use at the last sexual intercourse (if it was with a casual partner) was included in the construction of the risky behaviour variable. Condom use in risky sexual encounters is low, confirming the findings of other studies in sub-Saharan Africa (Fapohunda \& Rutenberg, 1999; Banda et al., 1999). It has been suggested that attitudes towards condom use may be to blame. Condoms are associated with casual or illicit sexual intercourse (Bond \& Dover, 1997; Preston Whyte, 1994). The contraceptive effect of condoms may also deter their use in strongly pronatalist societies (Cohen \& Trussell, 1996). Other factors include problems of disposal, fears and rumours about health effects, and reduction of sexual pleasure.

\section{Limitations}

This study has highlighted the association between perception of risk, sociodemographic and knowledge variables and reported sexual behaviour in Kenya. However, it has not demonstrated a causal link between risk perception and sexual behaviour, primarily because of the cross-sectional nature of the data. Reverse causality is possible between these variables. For example, high perception of risk could lead either to a change to safer sexual behaviour, or to fatalism and no change in behaviour. Similarly, risky sexual practices may lead individuals to perceive their risk of HIV infection to be high.

Endogeneity may also bias the results (Greene, 2000; Maddala, 1983). For example, having accurate knowledge about HIV transmission may lead to the consistent use of condoms during risky sexual encounters, which could in turn lead to lower perception of HIV risk. Clearly a simultaneous modelling approach may be useful in this case, where models of correlates of perception of risk and risky sexual behaviour are estimated at the same time. However, the authors are reasonably confident that the broad conclusions presented are likely to be reliable since the association between perception of risk and sexual behaviour is robust after controlling for a range of sociodemographic and knowledge variables.

The measure of risky sexual behaviour in the last 12 months used in this study has some limitations. The actual risk of exposure to HIV for an individual depends on a combination of factors. These include an individual's number and type of lifetime sexual partners, a partner's past or current sexual behaviour, consistency of condom use with each partner, the HIV status of the sexual partner, and indirectly, the level 
of HIV/AIDS prevalence in the population. Individuals reporting more than one sexual partner in the last 12 months may not necessarily have had an elevated risk if they used condoms consistently. Alternatively, an individual not reporting risky behaviour may be at high risk because of a partner whose behaviour is risky, as might be the case for many Kenyan women. In addition, people who do not report risky sexual behaviour in the last 12 months may have had risky sexual encounters prior to the 12-month period. Despite these limitations, this analysis is important because it examines the current prevalence of risky sexual behaviour among different sub-groups of the Kenyan population that has significant implications for HIV prevention strategies.

Finally, perception of HIV risk is not static but varies with context and over time. Individuals may perceive different levels of risk at different stages in their lives and with different sexual partners, even where their actual level of risk remains constant. Some studies have shown that the perception of risk of HIV may be high when a new sexual relationship is formed, but that the perception of risk diminishes as the relationship progresses (Ingham \& van Zessen, 1997; Fapohunda \& Rutenberg, 1999; Nzioka, 2001).

\section{Conclusion}

In Kenya, young men and women, and those who are not in marital unions, report high rates of risky sexual behaviour, including multiple partnerships and casual unprotected sexual intercourse. A strong association was demonstrated between perception of risk and sexual behaviour and this association is preserved after adjusting for varying sociodemographic characteristics. Many more women than men reported that they were at high risk of being infected with HIV, citing their partner's infidelity as the reason. Thus, as noted in the literature, the success of AIDS prevention may lie in addressing gender differences that inhibit women's roles in sexual decision-making and negotiation (UNAIDS, 2000a; Seidel, 1993). Equally, Kenya has a mix of cultural beliefs and practices emanating from the existence of over 41 different ethnic groups. The diversity in culture has been a major hindrance in the successful implementation of intervention programmes since no single programme has been found to suit all the different communities.

\section{References}

Abrams, D., Abraham, C., Spears, R. \& Marks, D. (1990) AIDS invulnerability: relationships, sexual behaviour and attitudes among 16-19 year olds. In: AIDS: Individual, Cultural and Policy Dimensions, pp. 35-52. Edited by P. Aggleton, P. Davies \& G. Hart. Falmer Press, London.

Aggleton, P., Slutkin, G. \& Davies, P. (1994) Risking everything? Risk behaviour, behaviour change and AIDS. Science 265, 341-345.

Ahlburg, D. A., Jensen, E. R. \& Perez, A. E. (1997) Determinants of extramarital sex in the Philippines. Hlth Trans. Rev. 7 (supplement), 467-479.

Ajayi, A., Marangu, L., Miller, J. \& Paxman, J. (1991) Adolescent sexuality and fertility in Kenya: a survey of knowledge, perceptions, and practices. Stud. Fam. Plann. 22, 205-216. 
Ali, M. M. \& Cleland, J. (2001) The link between postnatal abstinence and extramarital sex in Côte d'Ivoire. Stud. Fam. Plann. 32, 214-219.

ANARFI, J. K. (1993) Sexuality, migration and AIDS in Ghana: a socio-behavioural study. Hlth Trans. Rev. 3 (supplement), 45-67.

Auvert, B., Buve, A., Lagarde, E., Kahindo, M., Chege, J., Rutenberg, N., Musonda, R., Laourou, M., Akam, E. \& Weiss, H. A. (2001) Male circumcision and HIV infection in four cities in sub-Saharan Africa. AIDS 4 (supplement), 31-40.

Baltazar, G. M., Stover, J., Okeyo, T. M., Hagembe, B. O. N., Mutemi, R. \& Olola, C. H. O. (EDS) (1999) AIDS in Kenya: Background, Projections, Impact and Interventions. NASCOP, MOH and NCPD, Nairobi.

Banda, C., Bloom, S. S., Songolo, G., Mulendema, S., Cunningham, A. E. \& Boerma, J. T. (1999) National Trends in AIDS Knowledge and Sexual Behavior in Zambia 1996-98. Carolina Population Center, University of North Carolina at Chapel Hill, Chapel Hill, NC.

BAUNI, K. E. \& JARABI, B. O. (2000) Family planning and sexual behaviour in the era of HIV/AIDS: the case of Nakuru district in Kenya. Stud. Fam. Plann. 31, 69-80.

Becker, M. H. (1974) The health belief model and sick role behaviour. Hlth Educ. Mono. 2, 4.

BeCKer, M. H. \& JoSEPH, J. G. (1988) AIDS and behavioural change to reduce risk: a review. Am. J. publ. Hlth 78, $394-410$.

Blanc, A., Wolff, B., Gage, A., Ezeh, A., Neema, S. \& Ssekamatte-Ssebuliba, J. (1996) Negotiating Reproductive Outcomes in Uganda. Macro International, Inc., Calverton, MD.

Bond, V. \& Dover, P. (1997) Men, women and the trouble with condoms: problems associated with condom use by migrant workers in rural Zambia. Hlth Trans. Rev. 7, 377-391.

BongaArTs, J. (1995) Global Trends in AIDS Mortality. Research Division Working Paper 80, Population Council, New York.

Caldwell, J. C., Caldwell, P. \& Quiggin, P. (1989). The social context of AIDS in sub-Saharan Africa. Popul. Dev. Rev. 15, 185-234.

Caldwell, J. C., Orubuloye, I. O. \& Caldwell, P. (1999) Obstacles to behavioural change to lessen the risk of HIV infection in the African AIDS epidemic: Nigerian research. Hlth Trans. Rev. 9, 113-124.

Caldwell, J. C., Santow, G., Orubuloye, I. O., Caldwell, P. \& Anarfi, J. (eds) (1993) Sexual networking and HIV/AIDS in West Africa. Hlth Trans. Rev. 3 (supplement).

CARAËL, M. (1995) Sexual behaviour. In: Sexual Behaviour and AIDS in the Developing World, pp. 75-123. Edited by J. Cleland \& B. Ferry. Taylor and Francis, London.

Central Statistical Office (Zimbabwe) \& Macro International (1995) Demographic and Health Survey, 1994. Central Statistical Office, Harare, and Macro International, Columbia, MD.

Cleland, J. (1995) Risk perception and behavioural change. In: Sexual Behaviour and AIDS in the Developing World, pp. 157-192. Edited by J. Cleland \& B. Ferry. Taylor and Francis, London.

Cohen, B. \& Trussell, J. (eds) (1996) Preventing and Mitigating AIDS in Sub-Saharan Africa: Research and Data Priorities for the Social and Behavioural Sciences. National Academy Press, Washington, DC.

Dare, O. O. \& Cleland, J. G. (1994) Reliability and validity of survey data on sexual behaviour. Hlth Trans. Rev. 4 (supplement), 93-110.

Degrees du Lou, A. (1999) Reproductive health and AIDS in sub-Saharan Africa. Problems and prospects. Population (an English Selection) 11, 61-87.

Dixon-Mueller, R. (1996) The sexuality connection in reproductive health. In: Learning about Sexuality: A Practical Beginning, pp. 137-157. Edited by S. Zeidenstein \& K. Moore. Population Council and International Women's Health Coalition, New York. 
Dixon-Mueller, R. \& Wasserheit, J. (1990) The Culture of Silence: Reproductive Tract Infections among Women in the Third World. International Women's Health Coalition, New York.

Dodoo, F. N. (1998) AIDS Related Condom Use among Married Kenyan Men. African Population Policy Research Centre Working Paper 8, Population Council, Nairobi.

Eltinge, J. L., Parsons, V. L. \& JANG, D. S. (1997) Differences between complex-design-based and IID-based analyses of survey data: Examples from Phase I of NHANES III. STATS 19, $3-12$.

Family Health International (1999) A Dialogue Between the Sexes: Men, Women and AIDS Prevention. http://www.FamilyHealthInternational.org.uk

Fapohunda, B. M. \& Rutenberg, N. (1999) Expanding Men's Participation in Reproductive Health in Kenya. African Population Policy Research Centre, Nairobi.

Forsythe, S., Rau, B., Gold, E., Hayman, J. \& Alrutz, N. (1996) AIDS in Kenya: Socioeconomic Impact and Policy Implications. Family Health International, AIDSCAP, Arlington, VA.

GAGE, A. J. (1998) Sexual activity and contraceptive use: the components of the decision making process. Stud. Fam. Plann. 29, 154-166.

Gage, A. J. \& NJogu, W. (1996) Gender Inequalities and Demographic Behaviour: Ghana and Kenya. The Population Council, New York.

Government of Kenya/AIDS Control Unit, Ministry of Health, and National AidS Control Council (2001) AIDS in Kenya: Background, Projections, Impact, Interventions and Policy. AIDS Control Unit, Nairobi.

Greene, W. H. (2000) Econometric Analysis. Prentice Hall, NJ.

Hogsborg, M. \& Aaby, P. (1992) Sexual relations, use of condoms and perceptions of AIDS in an urban area of Guinea-Bissau with a high prevalence of HIV-2. In: Sexual Behaviour and Networking: Anthropological and Socio-cultural Studies on the Transmission of HIV, pp. 203-232. Edited by T. Dyson. Ordina, Liège.

Hulton, L. A., Cullen, R. \& Khalokho, W. S. (2000) Perceptions of the risks of sexual activity and their consequences among Ugandan adolescents. Stud. Fam. Plann. 31, 35-46.

Idele, P. A. (2002) Perception of Risk and Sexual Behaviour Change among Women and Men in Kenya. Unpublished $\mathrm{PhD}$ Thesis, University of Southampton, UK.

Ingham, R. \& Holmes, H. (1991) In-depth Analysis of Kenyan KAPB Survey Data. Departments of Psychology and Social Statistics, University of Southampton, Southampton, UK.

Ingham, R. \& VAN Zessen, G. (1997) Towards an alternative model of sexual behaviour: from individual properties to interactional processes. In: Sexual Interactions and HIV Risk: New Conceptual Perspectives in European Research, pp. 83-99. Edited by L. van Campendoudt, M. Cohen, G. Guizzardi \& D. Hauser. Taylor and Francis, London.

Ingham, R., Woodcock, A. \& Stenner, K. (1992) The limitations of rational decision making models as applied to young people's sexual behaviour. In: AIDS: Rights, Risk and Reason, pp. 163-173. Edited by P. Aggleton, P. Davies \& G. Hart. Falmer Press, London.

Irwin, K., Bertrand, J., Mibandumba, N., Mbuyi, K., Muremeri, C., Mukoka, M., Munkolenkole, K., Nzilambi, N., Bosenge, N. \& Ryder, R. (1991) Knowledge, attitudes and beliefs about HIV infection and AIDS among healthy factory workers and their wives, Kinshasa, Zaire. Social Sci. Med. 32, 917-930.

Kenya, P., Mulindi, S. A. Z., Onsongo, J. \& Gatei, M. (1998) HIVIAIDS in Kenya: Situation Analysis for NASCOP. Ministry of Health, Nairobi.

Kiragu, K. \& Zabin, L. S. (1995) Contraceptive use among high school students in Kenya. Int. Fam. Plann. Perspect. 21, 108-113. 
Konde-Lule, J. K. (1993) Focus group interviews about AIDS in Rakai district in Uganda. Social Sci. Med. 37, 679-684.

Konings, E., Blattner, W. A., Levin, A., Brubaker, G., Siso, Z., Shao, J., Goedert, J. J. \& ANDERSON, R. M. (1994) Sexual behaviour survey in a rural area of northwest Tanzania. AIDS 8, 987-993.

Korn, E. L. \& Graubard, B. I. (1995) Analysis of large health surveys: accounting for the sampling design. J. Roy. Stat. Soc., Series A 158, 263-295.

Lesthaeghe, R. J. (1989) Production and reproduction in sub-Saharan Africa: An overview of organising principles. In: Reproduction and Social Organisation in Sub-Saharan Africa, pp. 13-59. Edited by R. J. Lesthaeghe. University of California Press, Berkeley, CA.

Maddala, G. S. (1983) Limited Dependent and Qualitative Variables in Econometrics. Cambridge University Press, New York.

Mason, K. O. (1994) HIV transmission and the balance of power between women and men. Hlth Trans. Rev. 4 (supplement), 217-240.

MeEkers, D. (1994) Sexual initiation and premarital child bearing in sub-Saharan Africa. Popul. Stud. 48, 47-64.

Meekers, D. \& CALvès, A. (1997) Main girlfriends, girlfriends, marriage, and money: the social context of HIV risk behaviour in sub-Saharan Africa. Hlth Trans. Rev. 7 (supplement), 361-375.

National Council for Population and Development (NCPD), Central Bureau of Statistics (CBS) \& Macro International Inc. (MI) (1999) Kenya Demographic and Health Survey Report of 1998. NCPD, CBS and MI, Nairobi.

NzIOKA, C. (1996) Lay perceptions of risk of HIV infection and the social construction of safer sex: some experiences from Kenya. AIDS Care 8, 565-579.

NzIoKa, C. (2001) Perspectives of adolescent boys on the risks of unwanted pregnancy and sexually transmitted infections: Kenya. Reprod. Hlth Matters 9, 108-117.

Овво, С. (1993) HIV transmission through social and geographical networks in Uganda. Social Sci. Med. 36, 949-955.

Ocholla-Ayayo, A. B. C. (1976) Traditional Ideology and Ethics among the Southern Luo. Scandinavian Institute of African Studies, Uppsala.

Ocholla-Ayayo, A. B. C. (1997) HIV/AIDS risk factors and changing sexual practices in Kenya. In: African Families and the Crisis of Social Change, pp. 109-124. Edited by T. S. Weisner, C. Bradley \& P. L. Kilbride. Bergin \& Garvey, Westport, CT.

Ocholla-Ayayo, A. B. C. \& Schwarz, R. A. (1991) Report on Sex Practices and the Spread of STDs and AIDS in Kenya. University of Nairobi, Nairobi.

Okeyo, T. M., Baltazar, G. M., Stover J. \& Johnston, A. (eds) (1998) AIDS in Kenya: Background, Projections, Impact and Interventions. NASCOP, MOH and NCPD, Nairobi.

Orubuloye, I. O., Oguntimehin, F. \& SAdiQ, T. (1997) Women's role in reproductive health decision making and vulnerability to STD and HIV/AIDS in Ekiti, Nigeria. Hlth Trans. Rev. 7 (supplement), 329-336.

Pfeffermann, D., Skinner, C. J., Holmes, D. J., Goldstein, H. \& Rasbash, J. (1998) Weighting for unequal selection probabilities in multilevel models. J. Roy. Stat. Soc., Series B 60, 23-40.

Preston-Whyte, E. (1994) Gender and the lost generation: The dynamics of HIV transmission among black South African teenagers in Kwa-Zulu, Natal. Hlth Trans. Rev. 4, (supplement), 241-255.

Price, N. (1995) The Value of Children amongst the Kikuyu of Central Province, Kenya: an Anthropological Perspective on Fertility. Papers in International Development, No. 13. University of Wales, Swansea. 
Prohaska, T. R., Albrecht, G., Levy, J. A., Sugrue, N. \& Kim, J. (1990) Determinants of self-perceived risk for AIDS. J. Hlth social Behav. 31, 384-394.

ReID, E. (1999) Placing Women at the Centre of the Analysis. United Nations Development Programme (UNDP): HIV and Development Programme 6.

SEIDEL, G. (1993) Women at risk: Gender and AIDS in Africa. Disasters 17, 133-142.

Simonsen, J. N., Plummer, F. A., Ngugi, E. N., Black, C., Kreiss, J. K., Gakinya, M. N., Waiyaki, P., D’Costa, L. J., Ndinya-Achola, J. O., Piot, P. \& Ronald, A. (1990). HiV infection among lower socio-economic strata prostitutes in Nairobi. AIDS 4, 139-144.

Skinner, C. J., Holt, D. \& Smith, T. M. F. (1989) Analysis of Complex Surveys. Wiley, Chichester.

Smith, T. M. F. (1988) To weight or not to weight, that is the question. In: Bayesian Statistics, pp. 437-451. Edited by J. M. Bernado, N. H. Degroot, D. V. Lindley \& A. F. M. Smith. Oxford University Press, Oxford.

Stallings, R. A. (1990) Media discourse and the social construction of risk. Soc. Probl. 37, $80-95$.

Standing, H. \& Kisekka, M. N. (1989) Sexual Behaviour in Sub-Saharan Africa: A Review and Annotated Bibliography. Overseas Development Administration, London.

StataCorp (2001) STATA Statistical Software: Release 7·0. Stata Corportation, College Station, TX.

UNAIDS (1998) A Measure of Success in Uganda: The Value of Monitoring both HIV Prevalence and Sexual Behaviour. UNAIDS, Geneva.

UNAIDS (2000a) Report on the Global HIVIAIDS epidemic. Joint United Nations Programme on HIV/AIDS. UNAIDS, Geneva.

UNAIDS (2000b) Programme Monitoring and Evaluation Indicators. UNAIDS, Geneva.

UNAIDS \& WHO (2000) Guidelines for Second Generation HIV Surveillance (WHO/CDS/CSR/ EDC/2000.5 and UNAIDS/00·03E). UNAIDS/WHO Working Group on Global HIV/AIDS and STI Surveillance, Geneva.

WASSERHEIT, J. N. (1992) Epidemiological synergy: interrelationships between human immunodeficiency virus infection and other sexually transmitted diseases. Sex. Transm. Dis. 19, $61-77$. 